\title{
Comparison of three different farrowing systems: skin lesions and behaviour of sows with special regard to nursing behaviour in a group housing system for lactating sows
}

\author{
T. Nicolaisen ${ }^{1, \dagger} \odot$, B. Risch², E. Lühken ${ }^{1}$, C. van Meegen ${ }^{3}$, M. Fels ${ }^{1}$ and N. Kemper ${ }^{1}$ \\ ${ }^{1}$ Institute for Animal Hygiene, Animal Welfare and Farm Animal Behaviour, University of Veterinary Medicine Hannover, Foundation, Bischofsholer Damm 15, 30173 \\ Hannover, Germany; ${ }^{2}$ Clinic for Swine, Small Ruminants and Forensic Medicine, University of Veterinary Medicine Hannover, Foundation, Bischofsholer Damm 15, 30173 \\ Hannover, Germany; ${ }^{3}$ Statistical Consulting and Analysis Center, Department of Statistics, TU Dortmund University, Vogelpothsweg 87, 44221 Dortmund, Germany
}

(Received 14 June 2018; Accepted 7 March 2019; First published online 20 May 2019)

While group housing $(\mathrm{GH})$ is mandatory in the European Union for the greater part of pregnancy, single housing in farrowing crates (FCs) during lactation that restrict sows in most of their natural behaviour patterns is still practised on a large scale. Research is urgently needed to develop alternative farrowing systems that improve sows' welfare. Therefore, sows in three different farrowing systems - pens with $F C$, loose housing (LH) pens and GH for six sows - were compared regarding the level of skin injuries and their active and resting behaviour. A skin injury score was assessed for 15 body parts of 102 sows in six batches on 3 days (days 1, 14 and 34). In total, the active and resting behaviour of 77 sows in six batches was examined on 3 days (days 18, 25 and 32) between $0700 \mathrm{~h}$ and $1900 \mathrm{~h}$ by means of a scan sampling method. The suckling behaviour and the level of cross-suckling were analysed in GH by means of direct observation in four batches during three 4-h sampling periods (days 17, 24 and 31). No significant differences were found in total skin injuries when the sows entered the systems (day 1), but GH sows showed significantly higher total skin injuries compared to $F C$ and $L H$ sows in the middle (day 14) and at the end (day 34) of the lactation period. A significant difference between FC and LH sows was never seen. Differences were found for the proportion of different body postures between the three systems. The odds for lying in lateral recumbency versus standing and sitting versus standing were significantly higher for $F C$ and $L H$ sows compared to GH sows. Additionally, sows were significantly more likely to be standing as opposed to lying in lateral recumbency as the lactation period progressed. Cross-suckling was a frequent behaviour in $\mathrm{GH}$, seen in $35.0 \%$ of all successful suckling bouts. However, only an average of 0.56 piglets per successful suckling bout was observed cross-suckling, suggesting only a few piglets were engaged in cross-suckling. In conclusion, the skin injury score was only moderately increased in GH compared to FC and LH and comparable to pregnant group-housed sows, both free farrowing systems seemed to be an environmental enrichment for lactating sows and good management cannot prevent the occurrence of cross-suckling in a GH system, but can probably reduce it.

Keywords: pig, skin injuries, cross-suckling, loose housing, group housing

\section{Implications}

Free farrowing seems to be a proper instrument to enrich sows' environment and, therefore, possibly contribute to welfare for lactating sows. Group housing could be a practical alternative to individual housing of lactating sows, if a proper pen design prevents conflicts over resources and enables a stable hierarchy. Furthermore, good management is able to reduce the extent of cross-suckling in a group housing system.

\footnotetext{
† E-mail: thies.jesper.nicolaisen@tiho-hannover.de
}

\section{Introduction}

While group housing $(\mathrm{GH})$ is legally required for pregnant sows in the European Union during the period between four weeks after insemination and one week before farrowing (Council Directive 2008/120/EC), the individual housing of lactating sows in farrowing crates (FCs) throughout the entire lactation period is still permitted and, moreover, it is the dominating farrowing system in many countries. This common practice has led to animal welfare concerns because the $F C$ restricts the sow in a couple of natural behavioural patterns, 
e.g., in movement, defaecation behaviour, thermoregulation or nest-building behaviour (Baxter et al., 2011). Sows in crates are also more susceptible to stereotypes such as vacuum chewing or bar biting compared to group-housed sows (Arellano et al., 1992; Arey and Sancha, 1996). The main reason for the widely used restriction of lactating sows is the assumption of higher piglet mortality due to crushing in systems without confinement of the sows. However, a number of studies exist in which no difference in piglet mortality was found between pens with FCs and free farrowing pens (Weber et al., 2007; Pedersen et al., 2011). These studies illustrate that it is possible to find ways to improve the welfare of lactating sows without impairing the welfare of suckling piglets.

Different types of alternative farrowing systems have been investigated in numerous studies (Baxter et al., 2012), but $\mathrm{GH}$ best reflects the observed natural behaviour of domestic pigs kept under semi-natural conditions (Jensen, 1986), if the specific needs of the sows in this period (e.g., increased urge to move, separation close to farrowing, performing of nest-building behaviour and reintegration into the herd after farrowing) are taken into consideration.

Nonetheless, new challenges for animal welfare can arise when lactating sows are kept in groups. For example, aggressive conflicts among the sows can occur due to enabled social interaction, or the appearance of cross-suckling can have detrimental consequences for the piglets (Pedersen et al., 1998). On the other hand, there is evidence that piglets cope better with challenges at weaning (e.g., mixing), when pre-weaning socialisation with other litters occurred (Weary et al., 1999).

In this study, two prototypes of free farrowing systems a single loose housing (LH) pen and a GH system for six lactating sows (both developed by Big Dutchman International GmbH, Vechta, Germany) - were compared with conventional pens with a FC. In order to assess the system's influence on the sows' and piglets' behaviour and welfare, skin injuries and the active and resting behaviour of sows, as well as the occurrence of cross-suckling were evaluated.

\section{Material and methods}

\section{Animals and housing conditions}

All experiments were conducted on the experimental farm for pig breeding and pig husbandry of the Chamber of Agriculture for Lower Saxony in Wehnen, Germany, between July 2016 and August 2017.

Three different farrowing systems were tested: a conventional pen with $\mathrm{FC}$, a single $\mathrm{LH}$ pen, and a GH system for six lactating sows. The sows were a crossbreed between Landrace and Large White (genetics: BHZP, db. Viktoria).

All farrowing systems were located in the same building. Two compartments existed for each farrowing system. While $\mathrm{GH}$ and LH compartments included six pens each, there were eight pens in the $\mathrm{FC}$ compartments.
The FC pens (Figure 1a) were $260 \mathrm{~cm}$ long and $200 \mathrm{~cm}$ wide, had a fully slatted plastic floor and an open creep area $(160 \mathrm{~cm} \times 50 \mathrm{~cm})$, which was heated by an infrared light. The crate itself was $190 \mathrm{~cm}$ long and $80 \mathrm{~cm}$ wide. Tiles were recessed in the floor of the sow's lying area $(120 \mathrm{~cm} \times$ $110 \mathrm{~cm}$ ) to ensure thermal conduction.

In total, the LH pens (Figure 1b) were $270 \mathrm{~cm}$ long and $270 \mathrm{~cm}$ wide. A swing gate divided the pen and reduced the space that was actually accessible for the sow. The creep area $(100 \mathrm{~cm} \times 80 \mathrm{~cm})$ was located in the part of the pen that was not accessible for the sow. It was a closed creep area with one big opening on the front side and a small gate on a lateral side, and it was heated by an infrared radiation element (CE-REX ${ }^{\mathrm{TM}}$ IRX-300; Rexlan Europe, Sorø, Denmark). The floor of the $\mathrm{LH}$ pen was similar to that in the FC pens.

The GH (Figure 1c) consisted of two opposite rows of three pens each and a central common area. Each pen measured $202 \mathrm{~cm} \times 245 \mathrm{~cm}$, with a lockable large opening on the front side that granted access to a common area (size $610 \mathrm{~cm} \times$ $235 \mathrm{~cm}$ ). An approximately $20-\mathrm{cm}$-high roll at the bottom of the opening prevented the passing of piglets. An additional small opening on the front side of each pen granted access for the piglets to the common area. The floor of the pens was divided into a part with a fully slatted concrete floor (in the rear part of the pen, $120 \mathrm{~cm} \times 202 \mathrm{~cm}$ ) and a part with a fully slatted cast-iron floor (in the front of the pen, $125 \mathrm{~cm} \times 202$ $\mathrm{cm})$. The creep areas were similar to those in the LH pen. One part of the common area was only accessible for piglets (about $100 \mathrm{~cm} \times 235 \mathrm{~cm}$ ). The floor in the common area was a fully slatted concrete floor. Sows were tagged with an electronic ear tag and were only able to receive feed from an electronically controlled feeder in their own pen. Nipple drinkers were located in the pens and in the common area for both sows and piglets.

The sows in the LH pens and in the GH were not fixated at any point in time during the lactation period. Anti-crushing bars were installed in the pens of both systems and in the common area of the GH system.

All sows were fed with a standard diet for lactating sows (14.7 MJ ME $/ \mathrm{kg}, 16.0 \%$ crude protein). Farrowing crate and LH sows were fed twice a day, whereas GH sows were fed by an automatic feeder and were able to receive a certain percentage of their daily ration on three (until 10 days p.p.) and four (from day 11 p.p. until weaning) feeding periods (between $0800 \mathrm{~h}$ and $2000 \mathrm{~h}$ ) per day, respectively. On the first day p.p., sows received $3.0 \mathrm{~kg}$ feed per day, this amount increased to $7.0 \mathrm{~kg}$ on day 9 p.p. and to $8.5 \mathrm{~kg}$ on day 15 p.p. This was the maximal amount for FC and LH sows, whereas GH sows received up to $9.0 \mathrm{~kg}$ feed from day 17 p.p. until weaning. A commercial creep feed was offered to the suckling piglets from the tenth day of life.

Manipulable material was offered to sows and piglets for the entire lactation period (gunny sacks around birth, cotton ropes for sows and piglets and straw racks in $\mathrm{LH}$ and GH pens). 
Nicolaisen, Risch, Lühken, van Meegen, Fels and Kemper

(a)

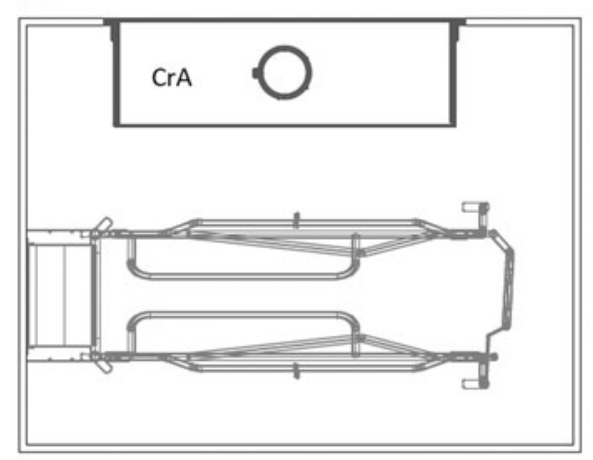

(b)

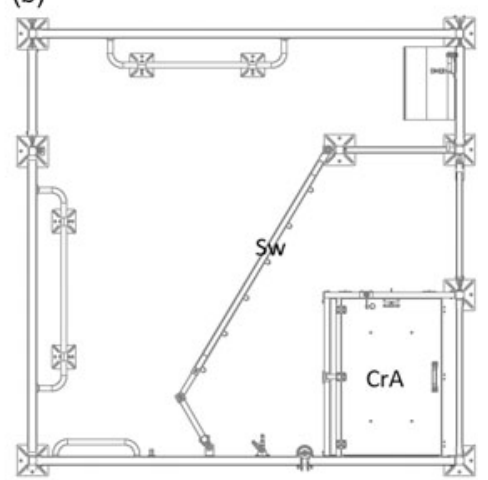

(c)

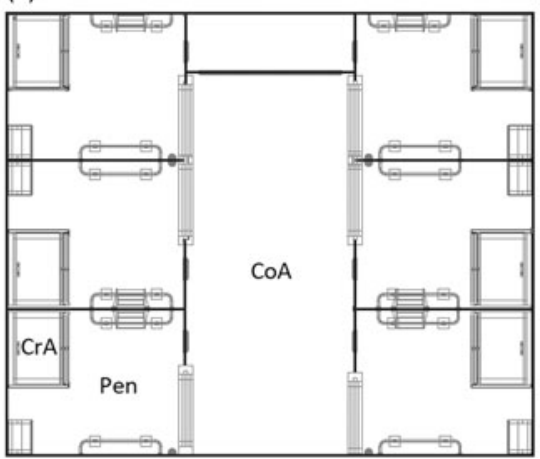

Figure 1 (a) Conventional pen with farrowing crate (FC); (b) Single loose housing (LH) pen; (c) Group-housing system for lactating sows (GH). CoA = common area. (C) Big Dutchman; $\mathrm{CrA}=$ creep area; $\mathrm{Sw}=$ swing gate.

\section{Farrowing, cross-fostering and piglet treatment}

The sows entered the pens on day 1 , one week before the expected farrowing date (day 7). Weaning took place after a lactation period of four weeks (day 34). Although there was no special treatment for the FC and LH sows, the GH sows were separated in the pens for the first $24 \mathrm{~h}$ after move in. Afterwards, the pens were opened for $48 \mathrm{~h}$ to enable socialisation among the six sows. Subsequently, the sows were penned in again to ensure that farrowing occurred in the pens (day 5). Re-opening of the GH took place for sows and piglets when the last born litter was at least five days old (day 13 in five batches and day 14 in one batch), and it stayed open for the remainder of the lactation period. Sows could move freely through the whole GH system (all pens and common area) when the pens were open. Due to the fact that sows were kept in small groups of four to five during pregnancy and distributed randomly to the farrowing systems, not all GH sows were unacquainted to each other.

At the beginning of the experiment, all multiparous sows had farrowed in FCs in previous lactations. All sows were allocated randomly to the farrowing systems, i.e., provided that a sow participated in the experiment for a second time, the sow was randomly assigned to one of the three farrowing systems again.

If cross-fostering was necessary, it was performed within $48 \mathrm{~h}$ after birth and only within the same farrowing system. Teeth clipping and ear tagging were performed on day 1 p.p., castration of male piglets on day 4 p.p. Tail docking was done under veterinary advisement on day 4 p.p.

\section{Video recording}

In total, 26 cameras (EverFocus ez.HD; Everfocus, Taiwan) and two video recorders (EverFocus ECOR FHD $16 \times 1$; Everfocus, Taiwan) were used to monitor and to record the sows' behaviour continuously. Eight cameras were installed in each of the two GHs (one for each pen and two for the common area). Three of the six pens were video recorded in the LH compartments (one camera per pen) and four of the eight FC pens were monitored in each compartment (one camera for two pens).

\section{Skin injuries}

One hundred two sows ( $36 \mathrm{GH}$ sows, 32 LH sows, $34 \mathrm{FC}$ sows; mean parities and SEM: $\mathrm{GH}=2.19( \pm 0.21), \mathrm{LH}=3.00$ $( \pm 0.41), F C=2.97( \pm 0.44))$ were examined for the level of skin injuries in six batches. All sows of the three tested farrowing systems were examined at three points in time per batch. The first scoring took place on the day the sows entered the farrowing pens (day 1), the second occurred $24 \mathrm{~h}$ after re-opening the pens in the GH (day 14 in five batches and day 15 in one batch) and the last scoring was conducted at weaning (day 34). The modified skin injury score was used based on the studies by Parratt et al. (2006) and Schrey et al. (2018), which ranged from 0 to 3 and is explained in Table 1. Fifteen parts of the body were inspected and scored: Head, ear, neck/shoulder, forelimb, flank, ham, hind limb on both body sides and the dorsal line. The skin injury score was assessed by one trained person. 
Table 1 Skin injury scoring system for sows (modified from Parratt et al., 2006 and Schrey et al., 2018)

\begin{tabular}{ll}
\hline \hline Score & \multicolumn{1}{c}{ Definition } \\
\hline 0 & No injuries \\
1 & Low number $(<5)$ of superficial scratches \\
2 & Medium number $(5-10)$ of superficial scratches \\
& or low number $(<5)$ of deep scratches \\
3 & High number $(>10)$ of superficial scratches or \\
& medium $(5-10)$ or high $(>10)$ number of deep scratches
\end{tabular}

Superficial scratch: Injury of upper dermal layers, slight reddening, possibly minimum bleeding or scab.

Deep scratch: Injury of deeper dermal layers with reddening/bleeding/scab necrotic or purulent processes possible.

No discrimination was made between new and healing scratches. Scars and shoulder ulcers were not regarded.

\section{Active and resting behaviour}

The active and resting behaviour of sows were analysed via video observations. Data were collected for 77 sows ( $36 \mathrm{GH}$ sows, 18 LH sows, $23 \mathrm{FC}$ sows; mean parities and standard error of mean (SEM): $\mathrm{GH}=2.19( \pm 0.21), \mathrm{LH}=3.00( \pm 0.52)$, $\mathrm{FC}=3.04( \pm 0.57))$ in six batches and assessed on three sampling days (day 18, 25 and 32) per batch between $0700 \mathrm{~h}$ and $1900 \mathrm{~h}$. A scan sampling method with 10-min-intervals over the $12 \mathrm{~h}$ was chosen to analyse body postures of each sow (standing, sitting, sternal recumbency or lateral recumbency).

The mean temperatures of all video observation periods were $23.45^{\circ} \mathrm{C}$ for $\mathrm{FC}, 22.41^{\circ} \mathrm{C}$ for $\mathrm{LH}$ and $23.96^{\circ} \mathrm{C}$ for $\mathrm{GH}$.

\section{Space utilisation in the group housing system}

Space utilisation in the $\mathrm{GH}$ was assessed in a sub-sampling that included four batches. The location of each GH sow (pen or common area) was determined on four sampling days (days $3,18,25$ and 32) per batch between $0700 \mathrm{~h}$ and $1900 \mathrm{~h}$. A scan sampling method with 10-min-intervals was chosen.

\section{Suckling behaviour and cross-suckling}

The occurrence and the level of cross-suckling were assessed by direct observations in the $\mathrm{GH}$ in four batches ( $n=24$ sows, mean parity and SEM: $2.3( \pm 0.26))$. Three 4 -h sampling periods (from $1200 \mathrm{~h}$ to $1600 \mathrm{~h}$ ) took place per batch on days 17, 24 and 31 . At the beginning of the measurements on day 17, litter size per sow was 13.1 (SEM \pm 0.25 ).

Different colours of animal marking spray were used to differentiate the six litters. Marking of piglets was finished $1 \mathrm{~h}$ before the observation period started. The following parameters were assessed: number of cross-suckling piglets, nursing synchronisation, location (pen or common area) and success/failure of each suckling bout. The number of crosssuckling piglets was assessed in the phase of milk ejection, which is characterised by quick and rhythmical sucking on the sows' teats (Fraser, 1980). The end of milk ejection was determined when piglets began to switch between teats or restarted udder massage (Maletínská and Špinka, 2001). The first sow which started a suckling bout became the focus animal. Every sow which started nursing within 4 minu after the focus animal began was regarded as being "synchronised" with it. The start of a suckling bout was determined by the following definition: a sow was lying in lateral recumbency and started characteristic grunting to attract her piglets (Maletínská and Špinka, 2001). A suckling bout was classified as being "successful" when the piglets could finish the phase of milk ejection on the udder.

\section{Statistical analysis}

The statistical analysis was carried out using $\mathrm{SAS}^{\circledR}$ Enterprise Guide software $\left(\mathrm{SAS}^{\circledR} \mathrm{EG}\right.$, Version 7.1, Copyright (๐) 2014; SAS Institute Inc., Cary, NC, USA) as well as the statistical open source software $R$ (Version 3.4.4) with the packages Ime4, ImerTest and mclogit (Bates et al., 2015; Elff, 2017; Kuznetsova et al., 2017; R Core Team, 2018).

Concerning skin injuries, a "cumulative rating index" (CRI) was generated for each sow at each time-point of examination by adding up the individual scores of the 15 body parts (CRI range: $0-45$ ). The CRI was used for further statistical analysis. First, it was tested whether the residual of the CRIs showed a normal distribution using the Kolmogorov-Smirnov-test (SAS ${ }^{\circledR}$ EG, PROC UNIVARIATE). Subsequently, the CRI of the three tested systems were compared by one-factor analysis of variance and the Fisher's Least Significance Test was chosen as a post-hoc-test to determine differences between the systems at 3 different examination days (SAS ${ }^{\circledR}$ EG,PROC ANOVA). Afterwards, a one sample $t$-test was conducted to detect differences between the three examination points within one of the three systems (SAS ${ }^{\circledR} E G, P R O C$ MIXED).

Differences between the three systems concerning injuries in single body parts were identified using the Exact-Fishertest (SAS ${ }^{\circledR} E G, P R O C$ FREQ). Bonferroni alpha adjustment for multiple comparisons was conducted and the significance level was determined as $P<0.0167$.

In addition, a linear model was adapted to model the impact of parity on the CRI taking account of the farrowing system and examination point as fixed effects and the individual sow as a random effect ( $R$, ImerTest::Imer).

Regarding active and resting behaviour, a multinomial logit model with random effects (i.e., individual sow) was calculated to model the body postures in dependence of the number of gestations, farrowing system and examination point ( $R$, mclogit::mblogit). Thereby, the odds of one body posture versus a reference category were modelled. Because standing is classified as the most strenuous body posture, it was chosen as a reference category.

A logistic mixed effect model was fitted to describe the odds of the preferred location "common area" versus "pen" dependent on the parity and the examination day ( $R$, Ime4::glmer).

Descriptive statistics were used to present the results of success of suckling, suckling frequency, location of suckling and cross-suckling.

\section{Results}

\section{Skin injuries}

An overview of the results is given in Figure 2. No significant differences of $\mathrm{CRI}$ were observed between the three farrowing 
Nicolaisen, Risch, Lühken, van Meegen, Fels and Kemper

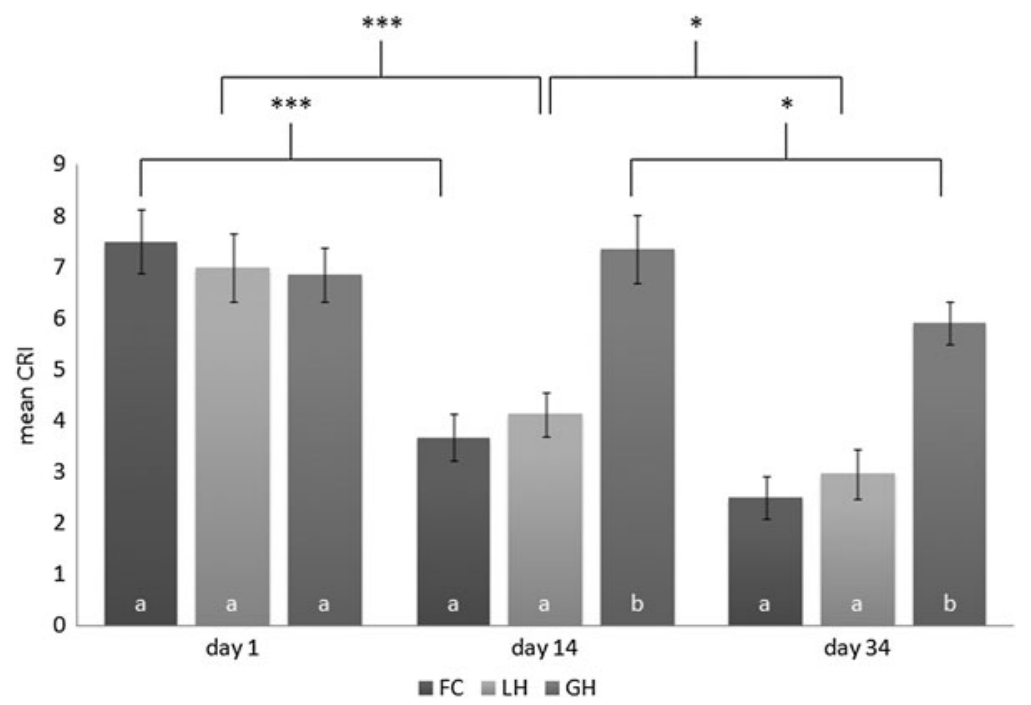

Figure 2 Mean cumulative rating score (CRI) and standard error of the mean in the three systems (pens with farrowing crate $=\mathrm{FC}(n=34$ sows), single loose housing pens $=\mathrm{LH}(n=32$ sows), group housing system $=\mathrm{GH}(n=36$ sows)) on different examination days. Different letters within one examination point mark significant differences $(P<0.05)$. Significant differences within one farrowing system between examination points are marked by ${ }^{*}(P<0.05)$ or $* * *(P<0.001)$.

systems on day 1 (mean values and SEM for CRI: $F C=7.50$ $( \pm 0.63), \mathrm{LH}=7.00( \pm 0.67), \mathrm{GH}=6.86( \pm 0.53)), P>0.05)$. Significant differences between $\mathrm{GH}$ and both single housing systems were found on day 14 . CRI was significantly higher in GH sows than in LH sows and FC sows (mean values and SEM: $\mathrm{FC}=3.68( \pm 0.45), \mathrm{LH}=4.13( \pm 0.44), \mathrm{GH}=7.36( \pm 0.66)$, $P<0.05)$. There was no significant difference between the FC sows and the LH sows on day $14(P>0.05)$. Significantly higher CRIs were found in $\mathrm{GH}$ compared with both single housing systems on day $34(P<0.05)$, but no difference existed between the CRIs of the two single housing systems (mean values and SEM: $\mathrm{FC}=2.50( \pm 0.41), \mathrm{LH}=2.97( \pm 0.48), \mathrm{GH}=5.92$ $( \pm 0.41), P>0.05)$.

A significant decline in CRI was found in $\mathrm{FC}$ between day 1 and day $14(P<0.001)$, but not between day 14 and day 34 $(P>0.05)$. On the other hand, the CRI of the LH decreased both between day 1 and day $14(P<0.001)$ and day 14 and day $34(P<0.05)$. No significant difference was detected in GH between day 1 and day $14(P>0.05)$, but CRI was significantly lower on day 34 compared to day $14(P<0.05)$.

An overview of skin injury scores of single body parts at different examination days is given in Supplementary Figures S1, S2 and S3. A difference in the skin injury scores of single body parts was not detected between FC sows and LH sows $(P>0.0167)$. The body parts "neck/shoulder" $(P<0.001)$, "forelimb" $(P<0.01)$ and "flank" $(P<0.0167)$ of GH sows were significantly more severely injured than those of FC sows on day 14 . At weaning, the body parts "neck/shoulder" $(P<0.001)$, "forelimb" $(P<0.01)$, "flank" $(P<0.01)$ and "ham" $(P<0.01)$ of GH sows showed significantly more severe lesions compared to $\mathrm{FC}$ sows. GH sows had significantly more severe forelimb lesions than LH sows at all examination points (days 1, 14 and 34: $P<0.0167$ ). Additionally, significantly higher injury scores were detected in GH sows compared to LH sows in the following body parts on the two latter examination points: "Head" (day 14:
$P<0.001$; day 34: $P<0.0167$ ) and "neck/shoulder" (days 14 and 34: $P<0.001$ ).

The results of the estimated linear mixed model (Supplementary Table S1) showed a significant effect of the parity on the injury score. If the number of gestation increased by 1 , the CRI increases by $0.258(P=0.0125)$.

\section{Active and resting behaviour}

A complete overview of percentages for single body postures on different examination days is given in Table 2 and an overview of the results for the multinomial logit model is given in Supplementary Table $\mathbf{S 2}$.

It could be shown that FC and LH sows had significantly higher odds of lateral recumbency versus standing than $\mathrm{GH}$ sows. The odd for lateral recumbency versus standing of an FC or LH sow increased by a factor of 1.87 and 1.82 $(P<0.001$ each), respectively, compared to the odd of a $\mathrm{GH}$ sow. According to this, it was more probable that an FC or LH sow was lying in lateral recumbency than standing compared to GH sows. Additionally, the examination day showed a significant negative influence on the odds of lateral recumbency versus standing. Therefore, on examination day 25 , it was much more likely that the sows preferred to stand than to lie in lateral recumbency compared to day 18 (odds 0.743 , $P<0.001$ ). For day 32 , it was even more extreme compared to day 18 (odds $0.617, P<0.001$ ).

Neither the farrowing system nor the examination day showed a significant influence on the odds of sternal recumbency versus standing.

The farrowing system had a significant impact on the odds of sitting versus standing. The odds of sitting versus standing when changing the farrowing system from $\mathrm{GH}$ to $\mathrm{FC}$ or LH increased by a factor of $2.59(P<0.001)$ and 1.69 $(P=0.034)$, respectively. Thus, $\mathrm{FC}$ and $\mathrm{LH}$ sows sat significantly more than standing compared to $\mathrm{GH}$ sows although 
Behavioural comparisons in three farrowing systems

Table 2 Mean percentage of sows' body postures on different examination days

\begin{tabular}{lcccccc}
\hline \hline & & \multicolumn{5}{c}{ Body posture } \\
\cline { 3 - 7 } $\begin{array}{l}\text { Examination } \\
\text { Day }\end{array}$ & $\begin{array}{c}\text { Farrowing } \\
\text { system }\end{array}$ & $\begin{array}{c}\text { LR } \\
(\%)\end{array}$ & $\begin{array}{c}\text { SR } \\
(\%)\end{array}$ & $\begin{array}{c}\text { TL } \\
(\%)\end{array}$ & $\begin{array}{c}\text { Si } \\
(\%)\end{array}$ & $\begin{array}{c}\text { St } \\
(\%)\end{array}$ \\
\hline \multirow{3}{*}{ Day 18 } & FC & 61.4 & 20.0 & 81.4 & 4.3 & 14.3 \\
& LH & 56.8 & 27.1 & 83.9 & 2.8 & 13.3 \\
Day 25 & GH & 45.0 & 33.9 & 78.9 & 2.2 & 18.9 \\
& FC & 54.5 & 25.5 & 80.0 & 4.3 & 15.7 \\
& LH & 49.1 & 31.7 & 80.8 & 3.7 & 15.5 \\
Day 32 & GH & 38.1 & 37.7 & 75.8 & 2.4 & 21.8 \\
& FC & 50.5 & 27.9 & 78.4 & 4.3 & 17.4 \\
& LH & 45.4 & 37.4 & 82.8 & 1.8 & 15.4 \\
& GH & 31.9 & 42.1 & 74.0 & 2.8 & 23.2 \\
\hline \hline
\end{tabular}

Farrowing system: $\mathrm{FC}=$ pen with farrowing crate; $\mathrm{LH}=$ loose housing pen; $\mathrm{GH}=$ group housing system.

Body posture: $L R=$ lateral recumbency; $S R=$ sternal recumbency; $T L=$ total lying; $\mathrm{Si}=$ sitting; $\mathrm{St}=$ standing .

it could not be shown that the examination point had an effect on the probability of sitting.

A significant impact of the parity was not found for any of the compared body postures.

\section{Space utilisation in the group housing system}

The pens were the preferred location of the sows on day 3 (pens: $69.2 \%$, common area: $30.8 \%$ ). The utilisation of pens and the common area was nearly equal on day 18 (pens: $50.2 \%$, common area: $49.8 \%$ ) and shifted towards the common area on day 25 (pens: $48.0 \%$, common area: $52.0 \%)$. The difference increased close to weaning on day 32 (pens: $42.7 \%$, common area: $57.3 \%$ ).

The results of the estimated logistic mixed effect model for the preferred location are shown in Supplementary Table S3. The odds of preferred location "common area" versus "pen" increased by a factor of $2.552(P<0.001)$ from day 1 to 18 , by a factor of $2.818(P<0.001)$ from day 1 to 25 , and by a factor of $3.648(P<0.001)$ from day 1 to 32 . Thus, the sows increasingly preferred the common area while the time of examination progressed.

No significant impact of the parity on the probability of a sow staying in the common area could be detected.

\section{Suckling behaviour and cross-suckling}

In total, 393 suckling bouts were observed in four batches. The majority of the suckling bouts were successful $(90.1 \%$, $n=354)$, only $9.9 \%(n=39)$ failed. Cross-suckling was observed in $35.0 \%(n=124)$ of all successful suckling bouts. The average number of cross-suckling piglets per successful suckling bout was 0.56 . In total, $68.6 \%$ of all detected crosssuckling events were caused by single piglets. The highest recorded number of cross-suckling piglets in a single crosssuckling event was five $(3.2 \%, n=4)$. In total, more suckling bouts took place in the common area $(52.4 \% ; n=205)$ than in the pens $(47.6 \% ; n=186)$, but large differences existed between the different weeks of lactation. In the second week
Table 3 Mean number and percentage of sows' suckling bouts in different grades of synchronisation

\begin{tabular}{lcc}
\hline \hline $\begin{array}{l}\text { Number of } \\
\text { synchronised sows }\end{array}$ & $\begin{array}{c}\text { Percentage of } \\
\text { suckling bouts (\%) }\end{array}$ & $\begin{array}{c}\text { Number of } \\
\text { suckling bouts }\end{array}$ \\
\hline 6 & 22.90 & $n=90$ \\
5 & 29.26 & $n=115$ \\
4 & 15.27 & $n=60$ \\
3 & 18.32 & $n=72$ \\
2 & 8.14 & $n=32$ \\
1 & 6.11 & $n=24$ \\
\hline \hline
\end{tabular}

of lactation, the majority of suckling bouts were kept in the pens (pens: $58.1 \%, n=90$; common area: $41.9 \%, n=65$ ). The number of suckling bouts in pens and in the common area shifted towards the common area in the third week of lactation (pens: $45.4 \%, n=54$; common area $54.6 \%, n=65$ ), and this gap became larger in the fourth week of lactation (pens: $35.9 \%, n=42$; common area $64.1 \%, n=75$ ). The synchronisation of suckling bouts was high. A complete overview of the level of synchronisation is given in Table 3 .

\section{Discussion}

\section{Skin injuries}

As expected, CRI declined in the two single housing systems over the course of time, because agonistic behaviour between sows could not occur anymore and the skin healed. No differences were found between the two single housing systems at any point in time. Although there is evidence that a crate itself can cause skin injuries (Anil et al., 2002), no such indication was found in this study.

In contrast to $\mathrm{FC}$ and $\mathrm{LH}$, no significant decline was found in GH between day 1 and day 14. Probably, the socialisation of the unacquainted sows prior to birth led to repeated agonistic behaviour among the sows and to new skin injuries. Weary et al. (2002) found the highest level of agonistic behaviour during the first $4 \mathrm{~h}$ after mixing lactating sows. It is known that unacquainted pigs start to fight immediately after grouping in order to form a social hierarchy that is established within $48 \mathrm{~h}$ (Meese and Ewbank, 1973). It could not be determined, if the constant level of skin injuries on day 14 compared to day 1 was still consequence of this agonistic behaviour during socialisation or if the fighting continued in the $24 \mathrm{~h}$ between reopening and second examination, and subsequently led to a renewed increase in skin injuries. However, a significant decrease in CRI was found in GH sows on day 34 compared to day 14 . A plausible explanation for this could be a stabilised social hierarchy among the six sows. Nevertheless, the CRI was still significantly higher compared to the sows in single housing systems at this stage. There is evidence that limited resources (e.g., food) can lead to high levels of aggression among sows even 28 days after mixing (Arey, 1999). In this study, although feed is not likely to be a source of competition (i.e., it is provided close to ad libitum 
and in single pens), the relatively small common area could have been a valued resource and thus a source of dispute causing conflicts and consequently new skin injuries. Former research, in group housed sows during gestation, showed that levels of agonistic behaviour and skin injuries increased when space allowance per sow declined (Weng et al., 1998). Comparing injuries of day 1 and day 34 of $\mathrm{GH}$ yielded no significant difference, i.e., it was not possible to detect differences between the late period of group-housed pregnant sows and group-housed lactating sows 5 weeks later. Moreover, the moderate values of CRI in the GH sows throughout the entire lactation indicate a low but constant grade of agonistic behaviour among them. Further research is necessary to determine if these moderate skin injury levels are an inevitable consequence of agonistic behaviour that may be needed to maintain a stable hierarchy or whether the skin injury levels can be reduced by solving the assumed conflict over resources (e.g., space).

A significant influence of parity was detected indicating that sows with a higher number of parities were more injured compared to sows with a lower number of parities. However, this finding does not limit the interpretation of our results, because FC and LH sows on average had a slightly higher number of parities than $\mathrm{GH}$ sows.

The comparison of respective body parts showed that GH sows particularly had higher skin injury scores in the front part of their bodies (head, shoulder/neck and forelimb) than sows of both single housing systems. These results indicate that the higher amount of skin injuries of GH sows is the result of agonistic behaviour. This assumption is supported by Turner et al. (2006) who found a significantly positive correlation between the frequency of reciprocal fighting and the grade of a lesion score for the front part of the body. There is a limited validity of this conclusion for the level of skin injuries of the forelimb due to the fact that a difference between GH sows and LH sows already existed when the sows entered the systems. A possible explanation for the significantly higher values of skin injuries of flank and ham in GH sows compared to FC sows could be agonistic behaviour in the manner of inverse parallel pressing (Jensen, 1980).

\section{Active and resting behaviour}

The results suggest that sows changed their active and resting behaviour in all three farrowing systems in the course of lactation. The odds for lying in lateral recumbency versus standing decreased significantly with time. This means, it was more probable that sows of all farrowing systems preferred to stand than to lie in lateral recumbency on days 25 and 32 in comparison to day 18. This phenomenon was found in previous research and was explained as a "piglet voidance strategy" of the sow (Blackshaw et al., 1994; Lambertz et al., 2015), i.e., the sow refuses the piglets' attempts to stimulate her udder by reducing the time spent in lateral recumbency. An explanation for the significantly higher odds for lateral recumbency versus standing and sitting versus standing in both single housing systems compared to $\mathrm{GH}$ could be enhanced piglet avoidance in
GH sows due to an additional harassment of the sow by suckling attempts of foreign piglets. This is supported by Bohnenkamp et al. (2013) who reported a continuous presence of foreign piglets on the sow's udder during nursing in a GH system.

Even though no significant difference for the odds of sternal recumbency versus standing could be detected, the descriptive analysis shows that the proportion for sternal recumbency was also higher in LH compared to $\mathrm{FC}$, and this indicates that additional factors could exist besides piglet avoidance.

Lateral recumbency is a state of total relaxation and inactivity, whereas sternal recumbency is a body posture in which sows are often awake, noticing and interacting with their environment (e.g., chewing on enrichment material or practising social interaction). The increased free moving space for LH and GH sows could have led to a higher level of participation in their environment compared to restricted FC sows expressed by an increased proportion of lying in sternal recumbency. However, Blackshaw et al. (1994) and Lambertz et al. (2015) found no significant differences of lying in sternal or lateral recumbency between crated sows and loose housed sows.

If the body posture "standing" is thought of as a proxy for activity in this study, the conclusion can be drawn that an unrestricted housing system (i.e., LH compared to FC) itself does not lead to a higher activity level. This is supported by Blackshaw et al. (1994) and Lambertz et al. (2015) who found no differences in standing between sows in FCs and loose housed sows. However, the GH system with its given possibilities of using different areas and interacting with five other sows could have led to an increased activity level in this study. Deviant results were found by Bohnenkamp et al. (2013) who found no difference in the periods spent standing between group-housed sows and sows in FCs.

At the beginning of our experiment, all multiparous sows farrowed in FCs in previous gestations. Recent research showed that sow behaviour is influenced by previous farrowing experiences and that this especially becomes visible when sows enter an unknown farrowing system (King et al., 2019). However, no influence of parity on the active and resting behaviour was found in our study.

\section{Space utilisation, suckling behaviour and cross-suckling}

Higher levels of successful suckling bouts with milk ejection (96.7\%) compared to our study $(90.1 \%)$ were found in a multi-suckling system by Arey and Sancha (1996). A possible reason for this difference could be a higher potential for conflict due to the smaller common area in this study. Although not systematically recorded, the authors of this study noticed many interrupted suckling bouts in the common area due to agonistic interactions between sows.

Referring to the results of the level of synchronisation, the conclusion can be drawn that the overwhelming majority of suckling bouts was synchronised with at least another sow $(93.9 \%)$. There is evidence that a higher grade of synchronisation could be a successful strategy to reduce cross-suckling, 
thus reducing the number of piglets that do not participate in a suckling attempt at their own mother (Maletínská and Špinka, 2001).

The observed shift in the preference of space utilisation and nursing location from pens to the common area during lactation could reflect natural behaviour patterns of sows after birth. Former research showed that sows separate from their herd prior to farrowing under semi-natural conditions (Jensen, 1986) and that the reintegration of sows and their piglets into a herd was seen as a gradual process under seminatural conditions that started by abandoning the farrowing nest on a mean piglet age of 10 days (Jensen and Redbo, 1987). A further explanation could be that the assumed lack of space in the common area (see Discussion section about skin injuries) and an instable hierarchy in the first stage of lactation resulted in a higher potential for conflict and subsequently forced the sows to avoid the common area. Crosssuckling was a frequently observed behaviour in this study. However, the small average number of cross-suckling piglets and the fact that $68.6 \%$ of cross-suckling events were caused by single piglets are signs for the moderate extent of this behaviour. Although piglets were not marked individually, the conclusion can be drawn that only a low number of piglets was engaged in cross-suckling. A comparable level of cross-suckling to the present study was found by Schrey et al. (2018) who observed an average number of 0.8 foreign piglets on the udder during suckling bouts. Bohnenkamp et al. (2013) found an average value of 0.3 to 0.4 foreign piglets on the udder during suckling. Despite the fact that the study by Bohnenkamp et al. (2013) was not cross-suckling orientated, the results do indicate a lower occurrence of this phenomenon compared to our study. A high incidence of cross-suckling was found in groups of three to four lactating sows by Maletínská and Špinka (2001): About $29 \%$ of all suckling was crosssuckling, with more than one-third of all piglets performing cross-suckling at least once.

Factors that are discussed to influence the extent of cross-suckling are milk yield of the sow, sow parity, litter size, litter age at co-mingling and farrowing conditions (van Nieuwamerongen et al., 2014). In this study, the litter equalisation took place within $48 \mathrm{~h}$ after birth. Thus, only small differences in litter size existed and this possibly prevented a higher level of cross-suckling. In this study, co-mingling occurred at a mean litter age of 7.2 days. The tight bonds between sows and their offspring develop within the first week of life (Horrell and Hodgson, 1992). Hence, it can be assumed that co-mingling management prevented a higher incidence of cross-suckling in our experiment. In this study, piglets were born in a structured multi-suckling system and spent the first days of life in a separate pen with their mothers, before they were socialised with other sows and their litters. The low levels of cross-suckling are in accordance with the results of Wattanakul et al. (1998), who ascertained that structural complexity of a multi-suckling system and adaption to the housing environment prior to co-mingling impeded cross-suckling.

\section{Conclusion}

The examination of the active and resting behaviour showed that an unrestricted housing system itself seemed to be an environmental enrichment for lactating sows and that this positive effect was even enhanced in a structured grouphousing system. Furthermore, the found skin lesions in $\mathrm{GH}$ were moderate and comparable to those of group-housed gestating sows living in a stable hierarchy. Thus, no negative influence of GH on sows' welfare was detected during lactation. Cross-suckling seemed to be inevitable in a grouphousing system for lactating sows, but an adequate management is able to reduce the extent of this behaviour.

\section{Acknowledgements}

The project was supported within the "Inno-Pig" project by funds of the German Government's Special Purpose Fund held at Landwirtschaftliche Rentenbank.

Thies Nicolaisen 0000-0001-9116-2491

\section{Declaration of interest}

No conflict of interests.

\section{Ethics statement}

The authors declare that the experiment was in accordance with current German law. This study was reviewed and received approval from the animal welfare officer of the University of Veterinary Medicine, Hannover, Foundation.

\section{Software and data repository resources}

None of the data were deposited in an official repository.

\section{Supplementary material}

To view the supplementary material for this article, please visit https://doi.org/10.1017/S1751731119000661

\section{References}

Anil L, Anil SS and Deen J 2002. Evaluation of the relationship between injuries and size of gestation stalls relative to size of sows. Journal of the American Veterinary Medical Association 221, 834-836.

Arellano PE, Pijoan C, Jacobson LD and Algers B 1992. Stereotyped behaviour, social interactions and suckling pattern of pigs housed in groups or in single crates. Applied Animal Behaviour Science 35, 157-166.

Arey DS 1999. Time course for the formation and disruption of social organisation in group-housed sows. Applied Animal Behaviour Science 62, 199-207.

Arey DS and Sancha ES 1996. Behaviour and productivity of sows and piglets in a family system and in farrowing crates. Applied Animal Behaviour Science 50, 135-145.

Bates D, Maechler M, Bolker BM and Walker SC 2015. Fitting linear mixedeffects models using Ime4. Journal of Statistical Software 67, 1-48.

Baxter EM, Lawrence AB and Edwards SA 2011. Alternative farrowing systems: design criteria for farrowing systems based on the biological needs of sows and piglets. Animal 5, 580-600.

Baxter EM, Lawrence AB and Edwards SA 2012. Alternative farrowing accommodation: welfare and economic aspects of existing farrowing and lactation systems for pigs. Animal 6, 96-117. 
Blackshaw JK, Blackshaw AW, Thomas FJ and Newman FW 1994. Comparison of behaviour patterns of sows and litters in a farrowing crate and a farrowing pen. Applied Animal Behaviour Science 39, 281-295.

Bohnenkamp A-L, Meyer C, Müller K and Krieter J 2013. Group housing with electronically controlled crates for lactating sows. Effect on farrowing, suckling and activity behavior of sows and piglets. Applied Animal Behaviour Science $145,37-43$.

The Council of The European Union 2008. Council Directive 2008/120/EC of 18 December 2008 laying down minimum standards for the protection of pigs. Official Journal of the European Union L47, 5-13.

Elff M 2017. Mclogit: mixed conditional logit models (R package version 0.5.1) Retrieved on 15 April 2018 from https://CRAN.R-project.org/package=mclogit.

Fraser D 1980. A review of the behavioural mechanism of milk ejection of the domestic pig. Applied Animal Ethology 6, 247-255.

Horrell I and Hodgson J 1992. The bases of sow-piglet identification. 2. Cues used by piglets to identify their dam and home pen. Applied Anima Behaviour Science 33, 329-343.

Jensen $P$ 1980. An ethogram of social interaction patterns in group-housed dry sows. Applied Animal Ethology 6, 341-350.

Jensen $P$ 1986. Observations on the maternal behaviour of free-ranging domestic pigs. Applied Animal Behaviour Science 16, 131-142.

Jensen $P$ and Redbo I 1987. Behaviour during nest leaving in free-ranging domestic pigs. Applied Animal Behaviour Science 18, 355-362.

King RL, Baxter EM, Matheson SM, Edwards SA 2019. Consistency is the key: interactions of current and previous farrowing system on litter size and piglet mortality. Animal 13, 180-188.

Kuznetsova A, Brockhoff PB and Christensen RHB 2017. ImerTest package: tests in linear mixed effects models. Journal of Statistical Software 82, 1-26.

Lambertz C, Petig M, Elkmann A and Gauly M 2015. Confinement of sows for different periods during lactation: effects on behaviour and lesions of sows and performance of piglets. Animal 9, 1373-1378.

Maletínská J and Špinka M 2001. Cross-suckling and nursing synchronisation in group housed lactating sows. Applied Animal Behaviour Science 75 17-32.

Meese GB and Ewbank R 1973. The establishment and nature of the dominance hierarchy in the domesticated pig. Animal Behaviour 21, 326-334.
Parratt CA, Chapman KJ, Turner C, Jones PH, Mendl MT and Miller BG 2006. The fighting behaviour of piglets mixed before and after weaning in the presence or absence of a sow. Applied Animal Behaviour Science 101, 54-67.

Pedersen LJ, Berg P, Jørgensen G and Andersen IL 2011. Neonatal piglet traits of importance for survival in crates and indoor pens. Journal of Animal Science 89 1207-1218.

Pedersen LJ, Studnitz M, Jensen KH and Giersing AM 1998. Suckling behaviour of piglets in relation to accessibility to the sow and the presence of foreign litters. Applied Animal Behaviour Science 58, 267-279.

R Core Team 2018. R: a language and environment for statistical computing. $R$ Foundation for Statistical Computing. Retrieved on 15 April 2018 from https:// www.R-project.org.

Schrey L, Kemper N and Fels M 2018. Behaviour and skin injuries of sows kept in a novel group housing system during lactation. Journal of Applied Animal Research 46, 749-757.

Turner SP, Farnworth MJ, White IMS, Brotherstone S, Mendl M, Knap P, Penny P and Lawrence $A B$ 2006. The accumulation of skin lesions and their use as a predictor of individual aggressiveness in pigs. Applied Animal Behaviour Science 96, 245-259. van Nieuwamerongen SE, Bolhuis JE, van der Peet-Schwering CMC and Soede NM 2014. A review of sow and piglet behaviour and performance in group housing systems for lactating sows. Animal 8, 448-460.

Wattanakul W, Edwards SA, Stewart AH and English PR 1998. Effect of familiarity with the environment on the behaviour and performance response of sows and piglets to grouping during lactation. Applied Animal Behaviour Science 61, 25-39.

Weary DM, Pajor EA, Bonenfant M, Fraser D and Kramer DL 2002. Alternative housing for sows and litters Part 4. Effects of sow-controlled housing combined with a communal piglet area on pre- and post-weaning behaviour and performance. Applied Animal Behaviour Science 76, 279-290.

Weary DM, Pajor EA, Bonenfant M, Ross SK, Fraser D and Kramer DL 1999. Alternative housing for sows and litters: 2 . Effects of a communal piglet area on pre- and post-weaning behaviour and performance. Applied Animal Behaviour Science 65, 123-135.

Weber R, Keil NM, Fehr M and Horat R 2007. Piglet mortality on farms using farrowing systems with or without crates. Animal Welfare 16, 277-279.

Weng RC, Edwards SA and English PR 1998. Behaviour, social interactions and lesion scores of group-housed sows in relation to floor space allowance. Applied Animal Behaviour Science 59, 307-316. 